\title{
Health-related development aid: what comes after it?
}

\author{
Steffen Fleßa
}

Received: 27 November 2013/Accepted: 9 December 2013/Published online: 23 December 2013

(C) Springer-Verlag Berlin Heidelberg 2013

The famous physician and theologian Dr. Albert Schweitzer (1875-1965) has been the hero and model for generations of medical missionaries and development workers. This talented man dedicated his entire life to the health of the people of Lambaréné and its catchment area. He had a natural gift for leadership and a tremendous capacity for financial management. Health economics and scientific management were almost irrelevant during his time and for a lot of his successors. However, the world has changed and health care in resource-poor countries has become highly complex so that health economics in developing countries builds the foundation of effective and efficient humanitarian and development aid. Consequently, donor agencies have employed health economists and health care managers in order to determine the most efficient allocation of scarce development resources. The final objective is still the same: health for the poor and vulnerable of this world. But the methods have changed significantly, i.e., there has been a paradigm shift between the era of Albert Schweitzer and his "followers" and the era of professionally managed healthrelated development aid today.

Nevertheless, it may be that we are facing a similar paradigm shift as so-called "developing countries" economically improve and the disease pattern changes dramatically. One has to ask what will happen to the thousands of professionals working in the field of health economics in development aid and the hundreds of organisations dedicated to this work if, one day, there will be no more need for healthrelated development assistance at all. This editorial elaborates on the history of health-related development aid, looks

\section{S. Fleßa (ه)}

Department of Health Care Management,

University of Greifswald, Friedrich-Loeffler-Straße 70,

17487 Greifswald, Germany

e-mail: Steffen.flessa@uni-greifswald.de at the current challenges and points at potential developments that might challenge our complete understanding of health care in resource-poor countries.

\section{History of health-related development aid}

Development aid has become a business with hundreds of thousands of professionals earning their living in this field. For instance, the author assessed organisations working in health-related development aid in Nairobi in 2012. The variety ranged from dozens of multilateral players (e.g. World Bank, WHO, Global Fund) and scores of national development agencies (e.g. GIZ, DANIDA, NORAD) to a multitude of specialized NGOs (e.g. German Leprosy and TB Relief Association) and made up more than 100 organisations. In 1993, the World Bank estimated annual health-related development aid to be some 5 billion US\$ [1]. In 2008 this amount had increased to roughly 7 billion [2]. Most of them compete for national resources (e.g. for donations from private supporters) and for the absorption capacity of their target countries. In addition, a tremendous number of consultants and consultancy firms provide services for these development organisations. Only the best with the most innovative ideas can find their market in the business of development aid.

This reality is contrary to our assumption of aid. Albert Schweitzer-as the pattern for at least two generations of development workers-did not have to compete with anybody. He was "good" just because he was there, i.e., if he had not been there, nobody would have supported the poor and vulnerable in Lambaréné. The main problem of this first era of development aid was the concentration on a few centres, whereas the majority of the population lived too far away to reach them. In Africa, for instance, it was 
estimated that less than $20 \%$ of the population had access to Western medicine by the early 1960s [3]. The location of the health care provider was hardly ever the result of a thorough analysis or scientific assessment, but the consequence of personal preferences as well as random [4]. In addition, the colonialists and missionaries at that time concentrated on big hospitals, frequently without reflection on the actual needs of the population [5]. The management was dominated by expatriates, and financing was mainly through external sources. Health economics and health care management where almost non-existent during that era.

The newly independent countries invested much to cover the entire population even in sparsely populated regions. It was recognized that hospital-based systems could not remain the backbone of the system. Instead, primary care facilities were planted all over the country [6]. This was frequently done by the national governments with national or international resources. The location of these new centres was selected with much more care [7], the allocation of funds to regions and districts was based more on the assessment of needs, and the design of the health care system followed professional standards set by the World Health Organisation (WHO) [8]. There is no doubt that the health situation of people strongly improved within the first two decades of the newly independent states. At the same time, elements of health economics and health care management became instruments in the hands of physicians, government officials, development workers and development agencies. This was supported by academic training, e.g., the University of Heidelberg started a Masters course in "Community Health and Health Management in Developing Countries" which included a number of subjects in economics and management.

In 1993 the leadership in international health shifted from the WHO to the World Bank [9]. The 1993 World Development Report [10] concentrated on "investing in health" and introduced Disability Adjusted Life Years (DALY) as the criterion for allocation of funds [11]. Based on the strong economic capacity of the World Bank, health economic analysis became a new standard for development aid. Many organisations followed the example of the Bank and hired professionals in that field. It took until the new millennium (and until a new Director General came) for WHO to follow this example, developing a strong health economic unit and adopting the DALY concept. From this point on, major donations in the field of health could not be approved without a health economic analysis (with the exemption of NGOs, such as missionary societies).

The new millennium brought another intensification of the economic focus of health-related development aid. Firstly, the so-called millennium development goals were precise enough to serve as the goals of economic models [12]. Secondly, the "Commission on Macroeconomics and
Health", which was installed by the WHO to demonstrate the impact of investments in health on income and wealth of nations, proved the strong capacity of economics [13]. Thirdly, public awareness rose, showing that humanitarian aid alone would never solve the problem of poor health in these countries. Politicians (e.g. the G8) and new multilateral organisations (e.g. the Global Fund) pointed at the need for efficient allocation of funds, effective programs and professional management. The so-called Paris Declaration made it clear that development aid is contra-productive unless it is accompanied by good leadership, i.e., health-related development work requires professional health care management [14].

A final step during the rise of economics in the field of health-related development aid was the establishment of innovative health care financing systems. In 1990 only some $5 \%$ of people in developing countries benefitted from any form of social protection [15]. Meanwhile, development aid has experimented with a number of alternative systems, from small-scale vouchers (e.g. focusing on maternal health care) [16] to comprehensive social insurances [17]. One can state that there are hardly any development agencies which are not running their own pilot health care financing schemes in developing countries. Certainly, the design of the respective system requires health economic expertise in the target countries, in the development agencies and from thousands of consultants earning their living in this field.

Consequently, thousands of health economists, health care managers and medical doctors with experience in related subjects are working for health-related development aid worldwide. They have to be expert in fields which are of little or no interest in the developed world. The young population requires expertise in the fields of mother and child health care (including the economics of vaccinations), in the modeling of infectious diseases, spatial accessibility (with large distances to be covered on foot) and management under conditions of extreme scarcity and other cultural values. These professionals have specialist training (e.g. Master in international health) and long-term experience in developing countries; they cannot simply be transferred to the developed world where chronic-degenerative diseases dominate, complex systems of social security exist and sub-specializations of all kinds are available.

\section{Future of health-related development aid}

It is obvious that the last 40 years have seen a strong shift from pure humanitarian aid to real development aid. This shift was accompanied by a stronger focus on health economics and health care management. But, at the same time, 
we experienced a number of changes that might have great influence on the "business of development aid". Firstly, many nations which we called "developing" some years ago have strongly improved in their economic capacity. Thailand, Malaysia, the Philippines and Ghana are examples of countries that were on the donors' list 25 years ago. Today, there is no more need to support their health care systems financially. Even countries which are still titled "least developed" such as Cambodia, Laos, Tanzania and Burundi are strongly improving with growth rates far beyond the respective figures in Europe [18]. More and more countries accept responsibility for the health of their population and have their own national means of financing health care services. Without doubt there is still a need for financial cooperation in countries like Cambodia, Afghanistan, Sudan and Malawi. But in comparison to the total health care expenditure, the support for these programs is much less today than it was before. One day it might be irrelevant.

Secondly, human resources have strongly improved in resource-poor countries. In almost all health care systems we find professional economists and managers, and many countries have started academic training programs in this field. Frequently experts do not come from the industrialized countries, but from that nation or neighboring countries. For instance, the National Institute of Public Health in Phnom Penh has developed a Masters course in hospital management. The lead consultant was from the Philippines.

Thirdly, health economics and health care management in developing countries have become more "normal" from the perspective of the developed world. For instance, most of these countries have reached quite far in the demographic transition and chronic-degenerative diseases have started to dominate [19]. Kenya, for instance, has started investing in cancer treatment centres and diabetes mellitus care. There is a need for professional health economists with expertise in this field. Mother and child health care as the former focus of many development specialists becomes less and less important, whereas the care of the elderly and other vulnerable groups becomes predominant-like in Europe. In future we might have less need for health economists who have specialized in developing countries, instead using health economists specialized in the particular disease or social protection system which the target country is interested in. If this scenario comes true, many development specialists might find themselves in competition with their professional colleagues from the developed world.

Finally, nations and the entire world accept more and more responsibility for the health of human beings. The discussion on "universal health coverage" [20] as the successor to health-related millennium development goals has shown clearly that it is generally accepted that the era of small-scale pilots and patchwork solutions is over. In order to provide universal coverage to the entire world population we need complex health care financing organisations with professional standards and management [21]. Some countries have started building up these institutions and realize that they need the international expertise of top professionals in that field. The National Hospital Insurance Fund in Kenya, for instance, did not ask development consultants to make a management review of their business. Instead, they contracted an international consultancy firm which offers its services worldwide with a strong focus on the USA. This assignment was-still-financed by development money, but the experts were not from the development field.

What will happen if this trend continues, if the countries-which we still call developing today-proceed with their economic growth and get richer, if the population gets even older and the disease panorama much more complex than today (such as in Europe!), and if the access to quality health care becomes more and more a human right fully financed by strong local governments? This might sound idealistic, but the lessons learnt from countries like Thailand strongly challenge our understanding of development work.

Health-related development aid might find itself unnecessary in its current focus. There will still be a need for professional advice worldwide, e.g. in the design and management of health care systems, health care financing and big institutions. This consultancy will require top experts in the particular field with a broad experience from the developed world. Thus, development agencies will compete with international consultancy organisations and will have to find new business fields in this international consultancy work, or they will be out of the market. Development experts will simply be consultants-and they will have to learn a lot of new fields of health economics.

This shift has already started. For instance, the German GIZ has launched a branch of "international services" providing consultancy services for countries that do not receive development aid. Even countries like Qatar request the expertise of GIZ - but we would never call this development aid. It is consultancy for an independent business partner. It is no more or less humanitarian or development oriented than most consultancy enterprises worldwide.

Without doubt, there will remain a branch of povertyoriented work coming closer to what we call development aid today. However, this work will not focus on a NorthSouth transfer of knowledge and funds but concentrate on poverty groups and vulnerables worldwide. International poverty eradication includes a strong focus on the health of 
the poor and vulnerable-but irrespective of which country they live in. This will require a mind-shift in the institutions of development aid.

What will all this mean for health economics and health care management? The increasing complexity and dynamics of health care systems worldwide will require more health economics and health care management than today. Health care providers, health insurances, Ministries of Health, civil society organisations and many others will need this expertise in order to safeguard efficient allocation of funds, professional management and a strong improvement in the quality of life of their people. Our subjects will remain of high importance in those countries which we call the developing world today. Each country or region will have its specialties (e.g. local diseases) requiring special expertise. But health economics and health care management will be more globalized and competitive. It will take some years-but hopefully we will experience it.

What would Albert Schweitzer say to all this? He dedicated himself to a "reverence for life" [22]. I am sure he would strongly appreciate that professional health economists and health care managers dedicate their lives to make the best use of resources for the wellbeing of mankind. But he would be even more delighted to reach a situation where there is no "exceptionality" for some countries or their health care systems. North-South aid will come to an end; global responsibility for the poor and vulnerable will prevail. This development will not require less, but even more health economics and health care management. As professionals and as developing agencies we should prepare ourselves.

\section{References}

1. Weltbank: Weltentwicklungsbericht: Investitionen in die Gesundheit. Weltbank, Washington D.C. (1993)

2. OECD: Recent trends in official development assistance to health (2011) http://www.oecd.org/dataoecd/1/11/37461859.pdf

3. McGilvray, J.C.: The quest for health. An interim report of a study process. German Institute for Medical Missions, Tübingen (1979)
4. Fleßa, S.: Gesundheitsreformen in Entwicklungsländern: eine kritische Analyse aus Sicht der kirchlichen Entwicklungshilfe. Lembeck, Frankfurt am Main (2002)

5. Morley, D., Lovel, H.: My name is today. Blackwell, London (1986)

6. Diesfeld, H.F.: Gesundheitsproblematik in der Dritten Welt. Wissenschaftl. Buchgesell, Darmstadt (1988)

7. Diesfeld, H.J.: The definition of the hospital catchment area and its population as a denominator for the evaluation of hospital returns in developing countries. Int. J. Epidemiol. 2(1), 47-53 (1973)

8. World Health Organisation, Alma-Ata 1978: primary health care. Report on the International Conference on Primary Health Care, 6-12. September 1978. Geneva: World Health Organisation (1978)

9. Zwi, A.B., Mills, A.: Health policy in less developed countries: Past trends and future directions. J. Int. Dev. 7(3), 299-328 (1995)

10. Bank, W.: World Development Report 1993: Investing in health. The World Bank, Washington DC (1993)

11. Murray, C.J.L., et al.: Development of WHO guidelines on generalised cost-effectiveness analysis. Health Econ. 9, 235-251 (2000)

12. Travis, P., et al.: Overcoming health-systems constraints to achieve the Millennium Development Goals. The Lancet 364(9437), 900-906 (2004)

13. Sachs, J.D.: Macroeconomics and health: Investing in health for economic development. Revista Panamericana de Salud Pública 12(2), 143-144 (2002)

14. Foresti, M., Booth, D., O'Neil, T.: Aid effectiveness and human rights-strengthening the implementation of the Paris Declaration, Overseas Development Institute (ODI), London (2009)

15. Barnum, H., Kutzin, J.: Public hospitals in developing countries. Johns Hopkins University Press, Washington DC (1993)

16. Schmidt, J.O., Hossain, A.: Vouchers as demand-side financing instruments for health care. In: Jalilian, H., Sen, V. (eds.) Improving health sector performance, pp. 76-100. ISEAS Publishing, Singapore (2011)

17. WHO: Universal health coverage. 2013; http://www.who.int/ health_financing/en/

18. Thompson, G.: Economic dynamism in the Asia-Pacific: the growth of integration and competitiveness. Routledge, London (2013)

19. Cervellati, M., Sunde, U.: Life expectancy and economic growth: the role of the demographic transition. J. Econ. Growth 16(2), 99-133 (2011)

20. WHO: Weltgesundheitsbericht 2008. Genf: Weltgesundheitsorganisation (2010)

21. Evans, D.B., Hsu, J., Boerma, T.: Universal health coverage and universal access. Bull. World Health Organ. 91, 546-546A (2013)

22. Schweitzer, A.: Reverence for life. Ardent Media, New York (1979) 